\title{
Did The Animal Move? A Cross-Wavelet Approach to Qeolocation Data Reveals Year-Round Whereabouts of A Resident Seabird
}

\section{Amédée Roy ( $\nabla$ amedee.roy@ird.fr )}

Institut de recherche pour le developpement https://orcid.org/0000-0003-3047-1463

Karine Delord

Centre d'Etudes Biologiques de Chizé: Centre d'Etudes Biologiques de Chize

Guilherme T. Nunes

Universidade Federal do Rio Grande do Sul

Christophe Barbraud

Centre d'Etudes Biologiques de Chize

Leandro Bugoni

Universidade Federal do Rio Grande

\section{Sophie Lanco-Bertrand}

Institut de recherche pour le developpement

\section{Research Article}

Keywords: activity pattern, breeding constraints, GLS, masked boobies, 32 saltwater immersion, sexual dimorphism, Sula dactylatra

Posted Date: April 14th, 2021

DOI: https://doi.org/10.21203/rs.3.rs-118834/v2

License: (9) This work is licensed under a Creative Commons Attribution 4.0 International License. Read Full License

Version of Record: A version of this preprint was published at Marine Biology on June 22nd, 2021. See the published version at https://doi.org/10.1007/s00227-021-03923-x. 
Marine Biology manuscript No.

(will be inserted by the editor)

1. Did the animal move? A cross-wavelet approach to geolocation data reveals year-round whereabouts of

${ }_{3}$ a resident seabird

4 Amédée Roy · Karine Delord .

5 Guilherme T. Nunes · Christophe

6 Barbraud · Leandro Bugoni · Sophie

7 Lanco-Bertrand

8 Received: date / Accepted: date

9 Abstract Considerable progress in our understanding of long-distance migra-

10 tion has been achieved thanks to the use of small lightweight geolocator devices

11 (GLS). Errors of geolocation are however important, difficult to estimate, have

12 a complex structure leading to poor precision and accuracy. Thus, the study of

A. Roy

Institut de Recherche pour le Développement (IRD)

MARBEC (Univ. Montpellier, Ifremer, CNRS, IRD)

Avenue Jean Monnet 34200 Sète, France E-mail: amedee.roy@ird.fr

K. Delord

Centres d'Etudes Biologiques de Chizé UMR7372 Centre National de la Recherche Scientifique 79360 Villiers en Bois, France

G. T. Nunes

Centro de Estudos Costeiros, Limnológicos e Marinhos Universidade Federal do Rio Grande do Sul (UFRGS), Campus Litoral Norte Avenida Tramandaí, 976 95625-000 Imbé, RS, Brazil

C. Barbraud

Centres d'Etudes Biologiques de Chizé UMR7372 Centre National de la Recherche Scientifique 79360 Villiers en Bois, France

L. Bugoni

Biological Sciences Institute and Seabirds and Sea Turtles Laboratory Universidade Federal do Rio Grande (FURG) Avenida Itália, km 8, Carreiros 96203-900 Rio Grande, RS, Brazil

S. Lanco-Bertrand

Institut de Recherche pour le Développement (IRD)

MARBEC (Univ. Montpellier, Ifremer, CNRS, IRD

Avenue Jean Monnet 34200 Sète, France 
34 Animals move to feed, to find mates, to avoid risks such as predation or ad-

36 their motion and navigation abilities (Bowler and Benton, 2005; Nathan et al., 37 2008). Birds in particular, including seabirds have great mobility and naviga38 tion skills, and many migratory birds are able to travel over long distances, 
39 to occupy distant areas at different seasons, returning repeatedly to the same

40 localities from year to year (Egevang et al., 2010; González-Solís et al., 2007;

41 Shaffer et al., 2006; Stenhouse et al., 2012; Weimerskirch and Wilson, 2000;

42 Wilson et al., 1998). In opposition, other seabirds can be referred as resident

43 (or sedentary) when their distribution and center of distribution remain more

44 or less the same all year round, and from year to year (Newton, 2008; Schacter

45 and Jones, 2018).

Resident behaviour might be explained by a reliable supply of food available locally all year, and/or if there are territorial advantages to regular yearround visits to their breeding site (Newton, 2008). It therefore might be related to an energy-saving strategy, where birds avoid metabolic costs associated with migration, but rather invest energy in remaining in seasonally less favorable habitats (Garthe et al., 2012). In particular, numerous tropical seabirds are

56 Pauly, 1987).

Migration may have evolutionary consequences at the species level, as it ${ }_{58}$ increases the probability of encountering individuals from other populations ${ }_{59}$ and, consequently, of gene flow. Therefore, being resident can have important 60 consequences on gene flow disruption between populations and on population ${ }_{61}$ genetic structures (Friesen et al., 2007), which in the end conditions the evo62 lutionary resources populations may rely on in changing environments. Resi${ }_{63}$ dency behaviour is thus of great interest for future investigations into the topic ${ }_{64}$ of population resilience. Current knowledge of seabird residency is however ${ }_{65}$ principally based on direct observations (Jaquemet et al., 2004; Olson et al., 66 2001), and to our knowledge few studies aimed at confirming or elucidating 
${ }_{86}$ by females (Weimerskirch et al., 2009), most of them did not demonstrate dif-

${ }_{87}$ ferences between sexes in foraging trips (Poli et al., 2017; Sommerfeld et al.,

${ }_{88}$ 2013; Young et al., 2010).

${ }_{89} \quad$ Yet, it is very challenging to accurately track year-round resident seabirds 90 such as masked boobies. Due to attachment and power limitations, the use ${ }_{91}$ of tracking devices such as GPS loggers and Argos transmitters is most often 92 limited to short time periods (from hours to months) (Ropert-Coudert et al., 93 2004; Wakefield et al., 2009; Wilson et al., 2002). Light-level data loggers or ${ }_{94}$ global location sensors (GLS) remains a preferred option for studying seabird 
95 spatial behaviour perennially since they are small enough to be attached on a 96 plastic ring, energy-efficient to be deployed for up to several years, and with ${ }_{97}$ reduced costs. The main idea to infer position from light data relies on the 98 analysis on twilights derived from highly frequent light intensity records (Hill, 99 1994; Lisovski et al., 2019). However, light signals may be subject to errors due to physical features (e.g. shade from vegetation or animal body covering the device), weather (e.g. cloud cover), and behaviour of animals (individuals nesting in burrows or being sat on the logger). As a consequence, positions derived from light records remain much less precise than positions estimated from GPS (Ekstrom, 2007; Lisovski et al., 2012; Phillips et al., 2004). For such reason, GLS and associated analytical methods are particularly relevant for elucidating migratory movements, as well as for movements that are in the order of magnitude of geolocation errors (e.g. $65+/-54 \mathrm{~km}$ in longitude and $358+/-499 \mathrm{~km}$ in latitude, as estimated in our study Fig. 1). In the latter case, the stumbling block remains in distinguishing movements from geolocation error to detect animal movements. Hopefully, many GLS also record external data such as saltwater immersion and sea surface temperature, which is crucial for improving geolocation estimations and/or interpreting GLS data (Guilford et al., 2009; Merkel et al., 2016).

Wavelet analyses have been widely used in ecology (e.g. Bertrand et al., 2008; Cazelles et al., 2008; Fablet et al., 2013; Jenouvrier et al., 2005) since this method is highly appropriate to analyze periodic patterns in biological time series that are often noisy, non-linear and non-stationary (Cazelles and Stone, 2003). Wavelet analysis provides appropriate tools for comparing the frequency contents of time-series, drawing conclusions about series' synchronicity at certain periods and across certain ranges of time. Therefore, it could be a relevant tool for investigating behavioural patterns from noisy GLS data. The overarching hypothesis being that significant synchronicity between saltwater 

ata).

immersion time-series and light-based position estimations reveals with higher confidence if the position deviation to the colony is related to real movement rather than geolocation error.

In this study, we used GLS to understand year-round at-sea movements of the masked booby. Objectives were to elucidate the post-breeding movements of masked boobies and sex-specific non-breeding behaviours, and to demonstrate the relevance of wavelet analysis as an analysis tool for GLS data derived from short-migrants or resident species.

\section{Material and Methods}

Study site

Fernando de Noronha (hereafter FdN, $03^{\circ} 50^{\prime} \mathrm{S}, 32^{\circ} 30^{\prime} \mathrm{W}$ ) is an offshore archipelago

(21 islands and islets, $18.2 \mathrm{~km}^{2}$ ) lying at $360 \mathrm{~km}$ east from the mainland city of Natal, Brazil. FdN is a clear priority for biodiversity conservation at the Brazilian federal state level (through the Ministry of Environment, ICMBIO) and scientific data are critical for improving the design of conservation policies. This archipelago hosts the highest diversity of seabirds in Brazil, with eleven species reported to breed there (Mancini et al., 2016). In order to elucidate the year-round whereabouts of masked boobies breeding on the archipelago, fieldwork was conducted on one of the secondary island, Meio island, which hosts one of the main masked booby breeding colony with 388 active nests (i.e. with eggs or chicks) censused in April 2018 (Antas, 1991, authors unpublished 
145 GLS data analysis

\section{GLS deployment}

Breeding adults raising two to seven weeks old chicks were caught on 4-6 May 2017 and fitted with GLS attached to a plastic ring. In total, 34 individuals were caught (16 females and 18 males) and two types of GLS were deployed ( $\mathrm{n}=20$ MK3006 and $\mathrm{n}=14$ MK3005 models from Biotrack Ltd., Wareham, UK). GLS weighted $2.5 \mathrm{~g}$ and were fixed to the plastic ring (2 g) with cable ties, the entire equipment corresponding to less than $0.4 \%$ of the body mass. All loggers recorded daylight level intensity, saltwater immersion (i.e. activity data) and sea surface temperature data.

Loggers measured daylight level intensity every $60 \mathrm{~s}$ and recorded the maximum light intensity for each 10 min for MK3006 and each 5 min for MK3005. For MK3006 wet/dry status is sampled every $3 \mathrm{~s}$ and the sum of immersion events for each 10 min receives a score between 0 and 200 (wet; immersion data $>0)$ and is stored. Temperature is recorded after 20 first minutes continuously wet, temperature wet timer resets anytime the device goes dry for $>3$ s. For MK3005, wet/dry status is sampled every $3 \mathrm{~s}$ and the sum of wet/dry duration is stored. Temperature is recorded after 25 minutes continuously wet, temperature wet timer resets anytime device goes dry for $>6 \mathrm{~s}$.

\section{Light-based geolocation}

Twilight times (i.e. sunrise and sunset) were determined using an arbitrary light intensity threshold of 2.5. A good choice for light threshold is often the lowest value that is consistently above any noise in the nighttime light levels, slightly above complete darkness (Pollet et al., 2014). The selection of the threshold was performed through the existing $\mathrm{R}$ library TwGeos (Lisovski 
et al., 2016). In situ calibration was done following Lisovski et al. (2019) recommendations. Relying on our knowledge of the phenology of masked boobies based on in situ observations, we assumed that birds stayed at their breeding place at least from 10 May 2017 to 15 June 2017. A sun elevation angle was computed for each tag using the Hill-Ekstrom calibration (i.e. minimization of latitude error variance), and used for the estimation of birds' geographic positions over the whole deployment. This was performed through the existing $\mathrm{R}$ library SGAT (Wotherspoon et al., 2016). Then, we assigned to each position mean temperature and proportion of time in water calculated between two twilights.

Finally, for each individual we evaluated the deviation between all observed twilight times and theoretical twilight at FdN with respect to the calibrated sun elevations (Fig. 1). The OSTIA global sea surface temperature reprocessed product provided by the Copernicus Marine Service was also used to compute the deviation between mean temperature recorded by the tags and the sea surface temperature from satellite observations ${ }^{1}$.

\section{Utilization distributions and maps of geolocation errors}

Utilization distributions were estimated by applying a two-dimensional Kernel Density Estimation (KDE) on observed positions from all GLSs with grid of mesh $0.5^{\circ}$ and a bandwidth of $2^{\circ}$ (Fig. 2). Percentage of presence within the Exclusive Economic Zone (EEZ) was also computed of each map, defined as the proportion of positions laying within the EEZ. The impact of measurement errors on geolocation estimates was illustrated by a map of geolocation error (Fig. 2). This map was estimated by sampling positions likely to be observed from a fixed GLS at FdN and by applying a two-dimensional KDE with same

1 https://resources.marine.copernicus.eu/ (product identifier SST $\_$GLO _ SST _L4_REP_OBSERVATIONS_010_001) 
parameters. In our case, a twilight error structure was defined by fitting a gamma distribution on all twilight times deviation estimated during the calibration period (Fig. 1). Twilight times observations were then simulated and used to estimate geolocations. Positions associated to deviation in temperature over $0.5^{\circ} \mathrm{C}$ were removed, based on the theoretical sensor accuracy given by the archival tag provider (Biotrack Ltd., Wareham, UK). Bhattacharyya coefficient was used for estimating quantitatively the dissimilarities between these distributions.

\section{Cross-wavelet analysis}

Wavelet analysis consists in a local scale decomposition of a signal through the computation of the wavelet coefficient:

$$
W_{y}(a, \tau)=\int_{-\infty}^{+\infty} y(t) \Psi_{a, \tau}(t)
$$

where $\Psi_{a, \tau}$ is the mother wavelet in its conjugate form, $\tau$ represents time, and $a$ is the scale of the wavelet (Fig. 3). The wavelet coefficient represents the contribution of a scale $a$ (i.e. the time periods on vertical axis in Figs 3 and 4) in the observed signal at time $\tau$ (i.e. the absolute time on horizontal axis in Figs 3 and 4). In other words, the more the signal $y(t)$ at time has a pattern with the same period as $\Psi_{a, \tau}$, the higher is $W_{y}(a, \tau)$. In practice, the Morlet wavelet is the most widely used mother wave, and is known for performing a good trade-off between temporal and scale resolutions (Torrence and Compo, 1998).

The cross-wavelet transform of two time series $x(t)$ and $y(t)$, with respective wavelet transforms $W_{x}$ and $W_{y}$ is finally defined by:

$$
W_{x, y}(a, \tau)=\frac{1}{\tau} \cdot W_{x}(a, \tau) \cdot W_{y}(a, \tau)
$$


The evaluation of the statistical significance of power cross-wavelet coefficients is then critical for interpreting them correctly (Cazelles et al., 2014; Rouyer et al., 2008). The significance test involves a null hypothesis of "no joint periodicity", and performs simulations of random time series in order to estimate the cross-wavelet coefficients range under the null hypothesis. By fixing a level of significance it is therefore possible to determine statistically significant correlation between the two observed time-series.

In our study, we evaluate cross-wavelet coefficient with the time-series of mean time in saltwater immersion, and longitude, since longitude is more accurately estimated than latitude (Hill, 1994). Thus, as a null hypothesis we simulated time-series by random sampling longitude and mean time in saltwater immersion. One out of two samples was sampled only from day data and the other only from night data. Analysis were conducted with the help of the WaveletComp R library (Rosch and Schmidbauer, 2018).

\section{Results}

Light-based geolocation

GLS were recovered $(\mathrm{n}=31$ loggers, i.e. $91 \%$ recovery rate) during the following breeding season during the second half of April 2018, and the light-based geolocation approach revealed that no masked booby had shown any migratory or wide-range movement (Fig. 2). The estimation of twilight deviations between observed and expected times at FdN over a year-round deployment did not differ much from deviations estimated during the calibration period (Fig. 1). The estimation of global error twilight structure lead to a gamma distribution of scale 2.66 and rate 0.32 , which corresponds to detection of dawn and dusk with about 10 min deviation in average and 20 min in worst cases, while maximal deviations over the whole deployment were about 30 min. Similarly, 
the distribution of temperature deviations over the deployment was very similar with the deviations observed during the calibration period with most value between $-0.5^{\circ} \mathrm{C}$ and $+0.5^{\circ} \mathrm{C}$. Spatially, the associated error range estimation and utilization distribution were thus very similar with a Bhattacharyya coefficient of 0.97 and 0.95 when comparing estimated maps respectively without and with filtering coordinates with respect to temperature data (Fig. 2). However, important deviations both in twilight times and temperature occurred when masked boobies spent more than $75 \%$ of the time in water between two consecutive twilights (Fig. 1), and associated to a slight deviation eastward in the utilization distribution (Fig. 2).

\section{Wavelet analysis}

The cross-wavelet analysis revealed local significant joint-periodicities (i.e. synchrony) between longitude and saltwater immersion time-series for every individual $(\mathrm{p}<0.01)$. This synchronicity appeared for different couple of specific periods and times and they are discernable in matrixes of cross-wavelet power coefficients (Fig. 3). The average matrixes of cross-wavelet power coefficient for all individuals show global patterns of joint synchronicity, and a strong relationship with the phenology of masked boobies (Fig. 4). Periods with almost no significant periodicity occurred mostly between March and July which correspond to the first stage of the breeding period (i.e. incubation: laying to hatching). In contrast, from July to March, which corresponds to the last stage of the breeding season until the end of the non-breeding season, significant joint-periodicity can be observed for both females and males. During this period, eastward movement (longitude increasing) corresponded to an increase of time spent on water, and equally westward movement (longitude decreasing) corresponded to a decrease of proportion of time spent on water. Interestingly, 
these joint-periodicities occurred mainly for periods of 2 to 8 days, with a modal period that increases from 2 days in July to 5 days in November. We could also observe specific period where all birds seem to stop showing jointperiodicity such as in the end of September or in mid-December. Differences by sex appeared when breeding is over, i.e. after fledging with higher power coefficient for females (Fig. 4).

These joint-periodicity illustrated that the tagged birds traveled way and back from the colony on consecutive trips of short length with ( $\sim 2-4$ days) to the east of the colony, with length and range depending on the sex and on the time of the year (Figs. 4 and 5). Trips had increasing average duration from the end of the breeding season to the pre-breeding period (Fig. 4) and associated increasing range (Fig. 5). In particular, during the pre-breeding period (January-March), females travelled significantly further to the east (Welch Two Sample t-test: $\mathrm{p}<0.001$ ) and spent more time in water than males (Fig. 5).

\section{Discussion}

GLS data and resident behaviour

Data from 31 GLS showed that masked boobies from FdN archipelago stayed in the vicinity of their breeding site both during breeding and non-breeding season. The cross-wavelet analysis revealed their short round trip of few days eastward to their breeding site.

GLS data have been only rarely used to demonstrate resident behaviour (Schacter and Jones, 2018). Existing studies have dealt with staging behaviour and most of them have estimated home range by applying KDE on a scatter of light-derived positions (Bächler et al., 2010; Stenhouse et al., 2012). Travelling periods are usually discriminated from resting periods by fixing empirical 
thresholds on distance to the colony (Leal et al., 2017) or on change in longitude (Guilford et al., 2009). Nevertheless, all insisted to be cautious when interpreting such data. Due to inherent limits of light-based geolocation accuracy, utilization distribution derived from GLS data often leads to a scatter of coordinates extended in latitude. In this study, we estimated maps of error range, and year-round utilization distribution of FdN's masked boobies, suggesting that masked boobies are resident at FdN. One could argue that it would be impossible to detect wide range movements in case seabirds would have changed of breeding location or simply skipped the breeding season. Indeed, because birds with archival tags needed to be recaptured, we only recovered tags that have been deployed on birds that bred at the same place for two consecutive years. However, previous observations (Kepler, 1969), as well as our own with recovery rate around 90

Our study reveals joint-periodicity between longitude and saltwater immersion time-series. One could think that these periodicities result from bias in the measure of light-level intensity when masked boobies sit on water and that they have not travelled eastward to FdN. This is however unlikely since shading due to immersion could explain a positive twilight deviation, but it is unlikely that it could explain the negative twilight deviation observed in Fig. 1. Indeed negative twilight error are theoretically impossible with GLS data, especially in environments with no artificial lights. Finally, GPS tracking of masked boobies in the same colony during the breeding season conducted in every April between 2017 and 2019 revealed that masked boobies from FdN forage almost exclusively at the east of the archipelago, and that they occasionally spent one night at sea, eastward of their breeding locations ( 8 out of 130 recorded trips, S. Bertrand, unpubl. data). Such nights at sea should be observable in GLS data, and in April few males showed indeed a joint periodicity of period $48 \mathrm{~h}$, which could correspond to trips lasting about $24 \mathrm{~h}$ (Fig. 
4). Based on our analysis, we are thus confident that masked boobies travelled way and back to the colony during the non-breeding season and beginning of breeding season, and that the eastward deviation consisted in real movements of about $150 \mathrm{~km}$ eastward to FdN.

Masked boobies' year-round residency

The year-round residence of masked boobies and the fact that they forage eastward of the archipelago might be related to the presence of twice more productive areas at the north-east of FdN due to the island effect of São Pedro São Paul offshore archipelago, which is known to trigger a local enrichment in the surrounding waters through an upwelling island effect (de Santana Campelo et al., 2019), which also support a resident population of Brown boobies Sula leucogaster there (Nunes et al., 2018). The intermittent way back to the colony is also in line with the territorial behaviour of masked boobies, known to come back to the colony intermittently during post-breeding period (Nelson, 2005).

Most previous studies on seabirds at FdN relied on colony-based sightings (Antas, 1991; Mancini et al., 2016; Sazima and de Almeida, 2008) and stable isotope analyses for trophic ecology (Mancini et al., 2013, 2014). Studies underlined the need for going further in the study of the ecology of seabirds at FdN, especially on their movement and the definition of their habitat, so as to improve conservation strategies (Mancini et al., 2016). This work provides a first answer on masked boobies year-round behaviour, inferring their nonmigratory behaviour and estimating their home range. In particular, masked boobies stay within the Brazilian Exclusive Economic Zone throughout the year, which brings valuable information for developing relevant conservation strategies such as designing Marine Protected Areas. 
Stage-related and sex-specific activity patterns

If some uncertainties remain on the exact home range of masked boobies, our study brings new insights on temporal, year-round, variation of their space use. In particular, we show a strong relationship between the duration of trips outside FdN and breeding constraints. Laying, incubating and hatching periods were associated with no joint periodicity, suggesting that the range and duration of foraging trips during these periods are below the error threshold of the signal provided by light and activity. These breeding stages are characterized by substantial thermal and energetic constraints linked to reproduction, since adults need to incubate or to brood and feed their chick. They mostly share time between defending the nest site or their chick and foraging at sea. Therefore, they are not expected to spend time resting at the sea surface for long periods during breeding (e.g. within the timeframe of two locations per day derived from GLS). Even if they forage far from their colony they have to come back frequently, and are likely to be observed at FdN. When chicks are older and can survive without the protection of their parents (i.e. rearing to fledging), the release of the thermal constraints was evidenced by joint-periodicity with gradually increasing periods.

Interestingly, when there was no constraint related to reproduction (i.e. no strict obligation to return to the nest), males and females showed slight differences in cross-wavelet power, particularly the few months prior breeding. During this specific period (January to March), the cross-wavelet analysis revealed higher power coefficients for females, which can be explained by longer trips and longer time spent on water. This confirms the fact that for this species, attendance at site prior to mate is larger for males than for females. Males are territorial and work at conquering and defending a nest place at that period (Nelson, 2005). By travelling further eastward and resting on water for 
longer period, females may reach and stay in more productive area (de Santana Campelo et al., 2019), at a period where they need to accumulate energy for the ovogenesis. Sexual differences in space use and activity patterns in the prebreeding period (which is not observed during the breeding period) provides a new light on reversed sexual dimorphism (RSD) of masked boobies. One of the functions proposed for RSD is niche segregation, especially to avoid intersexual competition and optimize the use of resources (Serrano-Meneses and Székely, 2006). Where many studies have failed to demonstrate differences in foraging behaviours of masked boobies in order to explain masked boobies' RSD, our own study provide relevant sex-specific activity patterns during the pre-breeding period i.e. pre-laying (Poli et al., 2017; Sommerfeld et al., 2013; Young et al., 2010).

\section{Wavelet analysis of geolocation data}

When dealing with GLS data deployed on resident or other non-migratory animals, the question might not be "where is the animal?" but rather "did the animal move?". In this situation, we might need external data in order to determine movement based on a relevant correlation. This is the case in our study, where we aimed at determining masked boobies' movements by studying the relationships between saltwater immersion and longitude. Our analytical framework could easily be used in order to investigate the space-uses of other resident seabirds, but also for elucidating if high deviations in position are due to shading caused by clouds (Lisovski et al., 2018). Indeed, it is a convenient and powerful tool for studying the sequentiality of noisy time-series such as light-derived positions, and for exploring significant synchronicity between such time-series, coupled with any other relevant external data (e.g. weather data, behavioural data). 
Despite the inaccuracy of GLS geolocation, our study shows it is appropriate for revealing year-round whereabouts of a resident tropical seabird over ong periods, such as during the non-breeding season. Indeed, thanks to timeseries with higher precision and reliability recorded by GLS such as temperaover-interpretation of GLS data.

ture and saltwater immersion we can extract more out of GLS data, particu-

larly by elucidating activity patterns, and saltwater immersion periodicity. We

brought new insights on masked booby movement patterns related to breeding constraints, and we revealed pre-breeding sex-specific movements that had not been observed to date. Finally, we demonstrated that wavelet analysis is a relevant way to extract more out of GLS data further broadly, to provide strong demonstration of animal movement or residency, and to avoid the possible

\section{Compliance with Ethical Standards}

Acknowledgments Fieldwork activities received the administrative and logistical support from the Fernando de Noronha administration, the Instituto Chico Mendes de Conservação da Biodiversidade (ICMBio, Brazil), the military firemen from Fernando de Noronha and the TAMAR Project. We also want to express grateful thanks to anonymous reviewers and to colleagues from IFREMER and IRD for having helped us significantly on the manuscript.

Funding This work is a contribution to the TRIATLAS project (funding by the European Union's Horizon 2020 research and innovation program - grant agreement No. 817578). This project has received funding from the Paddle Rise project - European Union's Horizon 2020 research and innovation program under Grant Agreement No 734271. This study was partially funded by IRD (Mixed International Laboratory Tapioca), CPER Celimer (France), 
Fundação O Boticário (Brazil), Brazilian National Research Council (CNPq,

${ }_{428}$ No. 422759/2016-3). L.B. is research fellow from CNPq (PQ 311409/2018-0).

Conflict of interest The authors declare that they have no conflict of interest. 436 cation.

Availability of data and material Data will be added to Movebank.

Code availability Code is available on our github page: https://github.com/AmedeeRoy/WaveLightGLS.

Authors' contributions A.R., S.B. and K.D. conceived the ideas and A.R. performed the analysis; A.R., G.T.N., K.D., C.B., K.D. and S.B. have been on fieldworks for collecting the data; A.R. led the writing of the manuscript. All authors contributed critically to the drafts and gave final approval for publi-

\section{References}

${ }_{438}$ Antas PTZ (1991) Status and conservation of seabirds breeding in Brazilian

${ }_{439}$ waters. ICBP Technical Publication 11:141-158

${ }_{440}$ Ashmole N (1971) Seabird ecology and the marine environment. Avian Biology

${ }_{441} \quad 1: 223-286$

${ }_{442}$ Bächler E, Hahn S, Schaub M, Arlettaz R, Jenni L, Fox JW, Afanasyev

${ }_{443}$ V, Liechti F (2010) Year-Round Tracking of Small Trans-Saharan Mi-

${ }_{444}$ grants Using Light-Level Geolocators. PLoS ONE 5(3):e9566, DOI

${ }_{445} \quad 10.1371 /$ journal.pone.0009566

${ }_{446}$ Ballance LT, Pitman RL, Fiedler PC (2006) Oceanographic influences on

${ }_{447}$ seabirds and cetaceans of the eastern tropical Pacific: A review. Progress

${ }_{448}$ in Oceanography 69:360-390, DOI 10.1016/j.pocean.2006.03.013 
Bertrand A, Gerlotto F, Bertrand S, Gutiérrez M, Alza L, Chipollini A, Díaz E, Espinoza P, Ledesma J, Quesquén R, Peraltilla S, Chavez F (2008) Schooling behaviour and environmental forcing in relation to anchoveta distribution: An analysis across multiple spatial scales. Progress in Oceanography $79(2-$ 4):264-277, DOI 10.1016/j.pocean.2008.10.018

Bowler DE, Benton TG (2005) Causes and consequences of animal dispersal strategies: Relating individual behaviour to spatial dynamics. Biological Reviews 80(2):205-225, DOI 10.1017/S1464793104006645

Cazelles B, Stone L (2003) Detection of imperfect population synchrony in an uncertain world. Journal of Animal Ecology 72:231-242, DOI 10.1046/j.1365-2656.2003.00763.x

Cazelles B, Chavez M, Berteaux D, Ménard F, Vik JO, Jenouvrier S, Stenseth NC (2008) Wavelet analysis of ecological time series. Oecologia 156(2):287304, DOI 10.1007/s00442-008-0993-2

Cazelles B, Cazelles K, Chavez M (2014) Wavelet analysis in ecology and epidemiology: Impact of statistical tests. Journal of the Royal Society Interface 11:20130585, DOI 10.1098/rsif.2013.0585

de Santana Campelo RP, Bonou FK, de Melo Júnior M, Diaz XFG, Bezerra LEA, Neumann-Leitão S (2019) Zooplankton biomass around marine protected islands in the tropical Atlantic Ocean. Journal of Sea Research 154:101810, DOI 10.1016/j.seares.2019.101810

Del Hoyo J, Elliott A, Sargatal J (1992) Handbook of the Birds of the World, vol 1. Lynx Editions, Barcelona

Diamond AW (1978) Feeding Strategies and Population Size in Tropical Seabirds. The American Naturalist 112(983):215-223

Egevang C, Stenhouse IJ, Phillips RA, Petersen A, Fox JW, Silk JRD (2010) Tracking of Arctic terns Sterna paradisaea reveals longest animal migration. Proceedings of the National Academy of Sciences 107(5):2078-2081, DOI 
10.1073/pnas.0909493107

Ekstrom P (2007) Error measures for template-fit geolocation based on light. Deep Sea Research Part II: Topical Studies in Oceanography 54(3-4):392403, DOI 10.1016/j.dsr2.2006.12.002

Fablet R, Chaigneau A, Bertrand S (2013) Multiscale analysis of geometric planar deformations: Application to wild animal electronic tracking and satellite ocean observation data. IEEE Transactions on Geoscience and Remote Sensing 52(6):3627-3636, DOI 10.1109/TGRS.2013.2274157

Friesen VL, Burg TM, McCOY KD (2007) Mechanisms of population differentiation in seabirds. Molecular Ecology 16(9):1765-1785, DOI 10.1111/j.1365294X.2006.03197.x

Garthe S, Ludynia K, Hüppop O, Kubetzki U, Meraz JF, Furness RW (2012) Energy budgets reveal equal benefits of varied migration strategies in northern gannets. Marine Biology 159(9):1907-1915, DOI 10.1007/s00227-0121978-6

González-Solís J, Croxall JP, Oro D, Ruiz X (2007) Trans-equatorial migration and mixing in the wintering areas of a pelagic seabird. Frontiers in Ecology and the Environment 5(6):297-301, DOI 10.1890/15409295(2007)5[297:TMAMIT]2.0.CO;2

Guilford T, Meade J, Willis J, Phillips R, Boyle D, Roberts S, Collett M, Freeman R, Perrins C (2009) Migration and stopover in a small pelagic seabird, the Manx shearwater Puffinus puffinus : Insights from machine learning. Proceedings of the Royal Society B: Biological Sciences 276(1660):12151223, DOI 10.1098/rspb.2008.1577

Hill RD (1994) Theory of Geolocation by Light Levels. In: Le Boeuf BJ, Laws RM (eds) Elephant Seals: Population Ecology, and Physiology, University of California Press, Berkeley, USA, pp 227-236 
Jaquemet S, Le Corre M, Weimerskirch H (2004) Seabird community structure in a coastal tropical environment: Importance of natural factors and fish aggregating devices (FADs). Marine Ecology Progress Series 268:281-292

Jenouvrier S, Weimerskirch H, Barbraud C, Park YH, Cazelles B (2005) Evidence of a shift in the cyclicity of Antarctic seabird dynamics linked to climate. Proceedings of the Royal Society B: Biological Sciences 272(1566):887-895, DOI 10.1098/rspb.2004.2978

Kepler CB (1969) The breeding biology of the blue-faced booby (Sula dactylatra personata) on Green Island, Kure atoll. Publications of the Nuttall Ornithologists Club 8

Leal GR, Furness RW, McGill RAR, Santos RA, Bugoni L (2017) Feeding and foraging ecology of Trindade petrels Pterodroma arminjoniana during the breeding period in the South Atlantic Ocean. Marine Biology 164(11):211, DOI $10.1007 / \mathrm{s} 00227-017-3240-8$

Lerma M, Serratosa J, Luna-Jorquera G, Garthe S (2020) Foraging ecology of masked boobies (Sula dactylatra) in the world's largest "oceanic desert". Marine Biology 167(6):87, DOI 10.1007/s00227-020-03700-2

Lewis S, Schreiber EA, Daunt F, Schenk GA, Orr K, Adams A, Wanless S, Hamer' KC (2005) Sex-specific foraging beiiaviour in tropical boobies: Does size matter? Ibis p 7, DOI 10.1111/j.1474-919x.2005.00428.x

Lisovski S, Hewson CM, Klaassen RHG, Korner-Nievergelt F, Kristensen MW, Hahn S (2012) Geolocation by light: Accuracy and precision affected by environmental factors. Methods in Ecology and Evolution 3(3):603-612, DOI 10.1111/j.2041-210X.2012.00185.x

Lisovski S, Wotherspoon S, Sumner M (2016) TwGeos: Basic data processing for light-level geolocation archival tags $\mathrm{R}$ package

Lisovski S, Schmaljohann H, Bridge ES, Bauer S, Farnsworth A, Gauthreaux SA, Hahn S, Hallworth MT, Hewson CM, Kelly JF, Liechti F, Marra PP, 
Rakhimberdiev E, Ross JD, Seavy NE, Sumner MD, Taylor CM, Winkler DW, Wotherspoon SJ, Wunder MB (2018) Inherent limits of light-level geolocation may lead to over-interpretation. Current Biology 28(3):R99-R100, DOI 10.1016/j.cub.2017.11.072

Lisovski S, Bauer S, Briedis M, Davidson SC, Dhanjal-Adams KL, Hallworth MT, Karagicheva J, Meier CM, Merkel B, Ouwehand J, Pedersen L, Rakhimberdiev E, Roberto-Charron A, Seavy NE, Sumner MD, Taylor CM, Wotherspoon SJ, Bridge ES (2019) Light-level geolocator analyses: A user's guide. Journal of Animal Ecology 89(1):221-236, DOI 10.1111/1365-2656.13036

Longhurst AR, Pauly D (1987) Ecology of Tropical Oceans. 574.52636 L6, Academic Press, San Diego

Mancini PL, Bond AL, Hobson KA, Duarte LS, Bugoni L (2013) Foraging segregation in tropical and polar seabirds: Testing the Intersexual Competition Hypothesis. Journal of experimental marine biology and ecology 449:186-193, DOI 10.1016/j.jembe.2013.09.011

Mancini PL, Hobson KA, Bugoni L (2014) Role of body size in shaping the trophic structure of tropical seabird communities. Marine Ecology Progress Series 497:243-257, DOI 10.3354/meps10589

Mancini PL, Serafini PP, Bugoni L (2016) Breeding seabird populations in Brazilian oceanic islands: Historical review, update and a call for census standardization. Ornithology Research 24(2):94-115, DOI $10.1007 / \mathrm{BF} 03544338$

Merkel B, Phillips RA, Descamps S, Yoccoz NG, Moe B, Strøm H (2016) A probabilistic algorithm to process geolocation data. Movement Ecology 4(1):26, DOI 10.1186/s40462-016-0091-8

Nathan R, Getz WM, Revilla E, Holyoak M, Kadmon R, Saltz D, Smouse PE (2008) A movement ecology paradigm for unifying organismal movement research. Proceedings of the National Academy of Sciences 105(49):19052- 
19059, DOI 10.1073/pnas.0800375105

Nelson B (2005) Pelicans, Cormorants, and Their Relatives. Oxford University Press

Newton I (2008) The Migration Ecology of Birds. Academic Press, London

Nunes GT, Bertrand S, Bugoni L (2018) Seabirds fighting for land: Phenotypic consequences of breeding area constraints at a small remote archipelago. Scientific Reports 8:665, DOI 10.1038/s41598-017-18808-7

Olson PA, Ballance LT, Hough KR, Dutton PH, Reilly SB (2001) Summary of seabird, marine turtle, and surface fauna data collected during a survey in the eastern tropical pacific ocean July 8 - December 9, 2000. NOAA Technical Memorandum NMFS p 67

Phillips R, Silk J, Croxall J, Afanasyev V, Briggs D (2004) Accuracy of geolocation estimates for flying seabirds. Marine Ecology Progress Series 266:265272, DOI $10.3354 / \operatorname{meps} 266265$

Poli CL, Harrison AL, Vallarino A, Gerard PD, Jodice PGR (2017) Dynamic oceanography determines fine scale foraging behavior of Masked Boobies in the Gulf of Mexico. PLOS ONE 12(6):e0178318, DOI 10.1371/journal.pone. 0178318

Pollet IL, Hedd A, Taylor PD, Montevecchi WA, Shutler D (2014) Migratory movements and wintering areas of Leachs StormPetrels tracked using geolocators. Journal of Field Ornithology 85(3):321-328, DOI 10.1111/jofo.12071 Ropert-Coudert Y, Wilson RP, Daunt F, Kato A (2004) Patterns of energy acquisition by a central place forager: Benefits of alternating short and long foraging trips. Behavioral Ecology 15(5):824-830, DOI 10.1093/beheco/arh086

Rosch A, Schmidbauer H (2018) WaveletComp R package

Rouyer T, Fromentin JM, Stenseth NC, Cazelles B (2008) Analysing multiple time series and extending significance testing in wavelet analysis. Marine Ecology Progress Series 359:11-23, DOI 10.3354/meps07330 
Sazima I, de Almeida LB (2008) The bird kraken: Octopus preys on a sea bird at an oceanic island in the tropical West Atlantic. Marine Biodiversity Records 1:e47, DOI 10.101/S1552a20a005458

Schacter CR, Jones IL (2018) Confirmed year-round residence and land roosting of Whiskered Auklets ( Aethia pygmaea ) at Buldir Island, Alaska. The Auk 135(3):706-715, DOI 10.1642/AUK-17-235.1

Serrano-Meneses MA, Székely T (2006) Sexual size dimorphism in seabirds: Sexual selection, fecundity selection and differential niche-utilisation. Oikos 113(3):385-394, DOI 10.1111/j.0030-1299.2006.14246.x

Shaffer SA, Tremblay Y, Weimerskirch H, Scott D, Thompson DR, Sagar PM, Moller H, Taylor GA, Foley DG, Block BA, Costa DP (2006) Migratory shearwaters integrate oceanic resources across the Pacific Ocean in an endless summer. Proceedings of the National Academy of Sciences 103(34):12799-12802, DOI 10.1073/pnas.0603715103

Sommerfeld J, Kato A, Ropert-Coudert Y, Garthe S, Hindell MA (2013) Foraging Parameters Influencing the Detection and Interpretation of AreaRestricted Search Behaviour in Marine Predators: A Case Study with the Masked Booby. PLoS ONE 8(5):e63742, DOI 10.1371/journal.pone.0063742 Stenhouse IJ, Egevang C, Phillips RA (2012) Trans-equatorial migration, staging sites and wintering area of Sabine's Gulls Larus sabini in the Atlantic Ocean: Sabine's Gull migration. Ibis 154(1):42-51, DOI 10.1111/j.1474919X.2011.01180.x

Torrence C, Compo GP (1998) A practical guide to wavelet analysis. Bulletin of the American Meteorological society 79(1):61-78

Wakefield E, Phillips R, Matthiopoulos J (2009) Quantifying habitat use and preferences of pelagic seabirds using individual movement data: A review. Marine Ecology Progress Series 391:165-182, DOI 10.3354/meps08203 
Weimerskirch H, Wilson RP (2000) Oceanic respite for wandering albatrosses. Nature 406(6799):955-956, DOI 10.1038/35023068

Weimerskirch H, Le Corre M, Gadenne H, Pinaud D, Kato A, Ropert-Coudert Y, Bost CA (2009) Relationship between reversed sexual dimorphism, breeding investment and foraging ecology in a pelagic seabird, the masked booby. Oecologia 161(3):637-649, DOI 10.1007/s00442-009-1397-7

Wilkinson BP, Haynes-Sutton AM, Meggs L, Jodice PGR (2020) High spatial fidelity among foraging trips of Masked Boobies from Pedro Cays, Jamaica. PLOS ONE 15(4):e0231654, DOI 10.1371/journal.pone.0231654

Wilson R, Grémillet D, Syder J, Kierspel M, Garthe S, Weimerskirch H, Schäfer-Neth C, Scolaro J, Bost C, Plötz J, Nel D (2002) Remote-sensing systems and seabirds: Their use, abuse and potential for measuring marine environmental variables. Marine Ecology Progress Series 228:241-261, DOI $10.3354 /$ meps228241

Wilson RP, Culik BM, Kosiorek P, Adelung D (1998) The over-winter movements of a chinstrap penguin (Pygoscelis antarctica). Polar Record 34(189):107-112, DOI 10.1017/S0032247400015242

Wotherspoon SJ, Sumner MD, Lisovski S (2016) SGAT: Solar/Satellite geolocation for animal tracking $\mathrm{R}$ package

Young H, Shaffer S, McCauley D, Foley D, Dirzo R, Block B (2010) Resource partitioning by species but not sex in sympatric boobies in the central Pacific Ocean. Marine Ecology Progress Series 403:291-301, DOI $10.3354 /$ meps 08478 

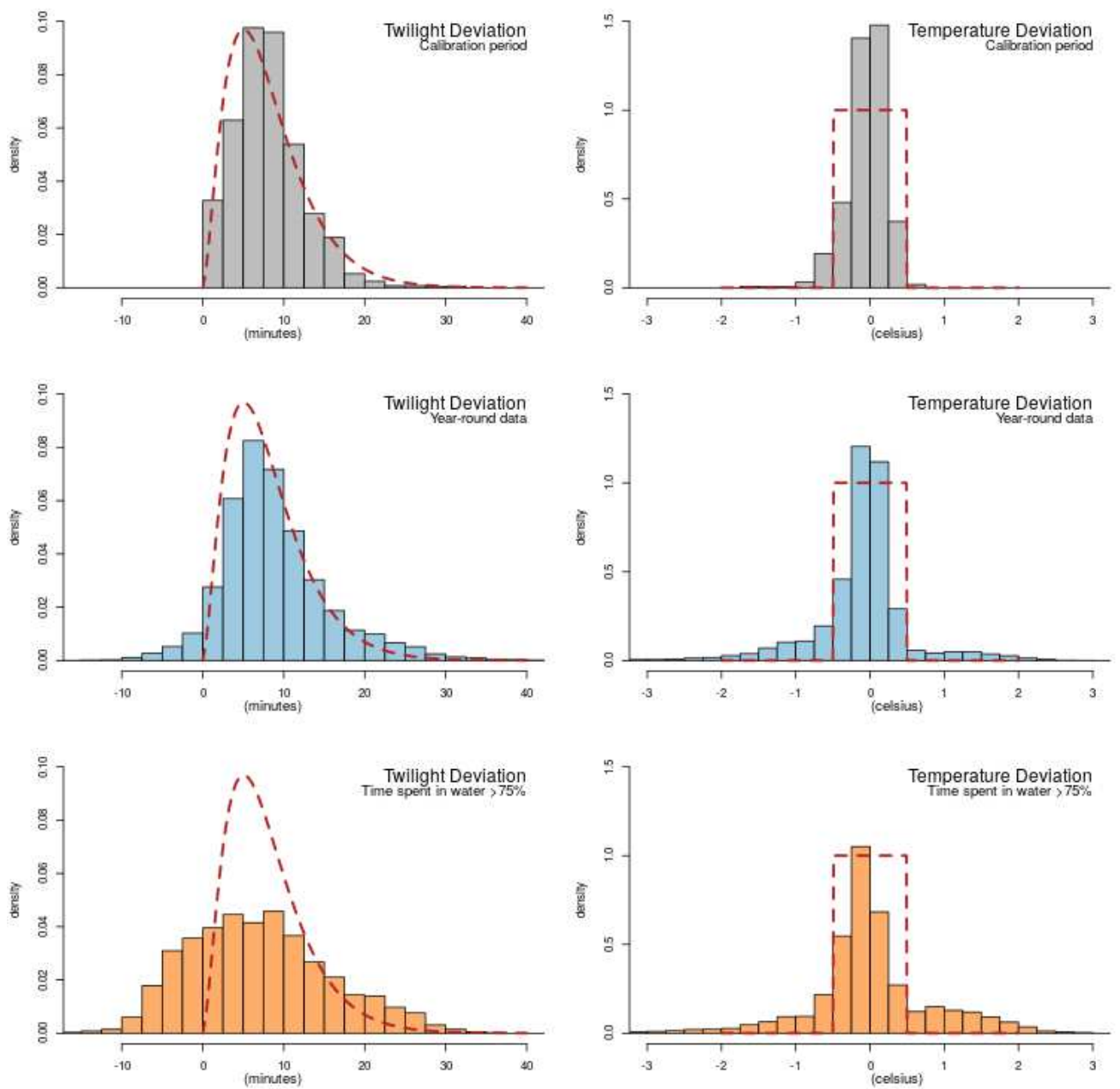

Fig. 1 Twilight times and temperature deviation at Fernando de Noronha. Grey histograms consider the calibration period only (10 May 2017 to 15 June 2017). Blue histograms consider all deployment period (05 May 2017 to 24 April 2018). Orange histograms consider periods where the mean saltwater immersion time is above $75 \%$. Red-dotted curves correspond to the error structure used in Fig. 2 
(a) Error Range Estimation

Presence In EEZ : $83 \%$

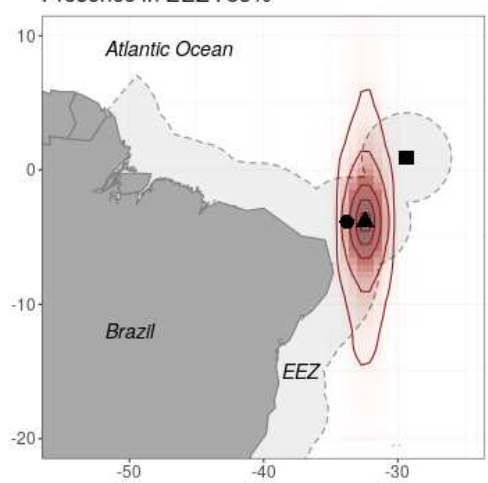

(d) Error Range Estimation Presence in EEZ : $95 \%$

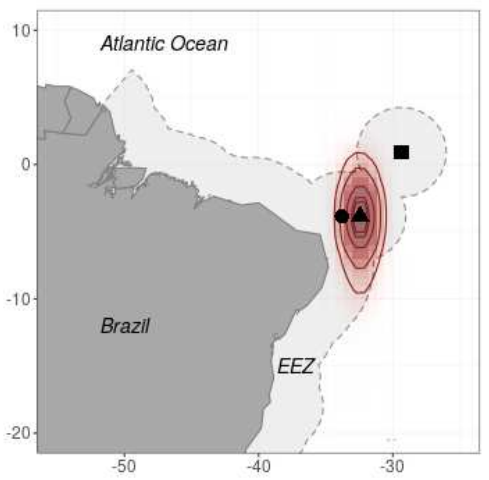

(b) Utilization Distribution

Presence in EEZ : $77 \%$

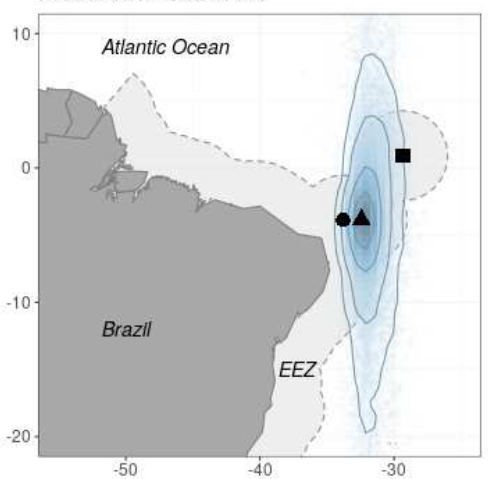

(e) Utilization Distribution Presence in EEZ : $93 \%$

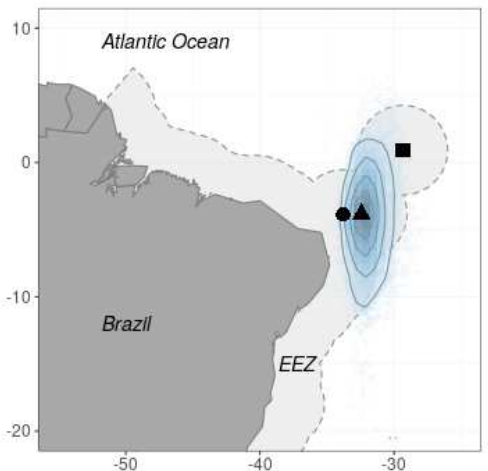

(c) Wet Utilization Distribution

Presence In EEZ : $67 \%$

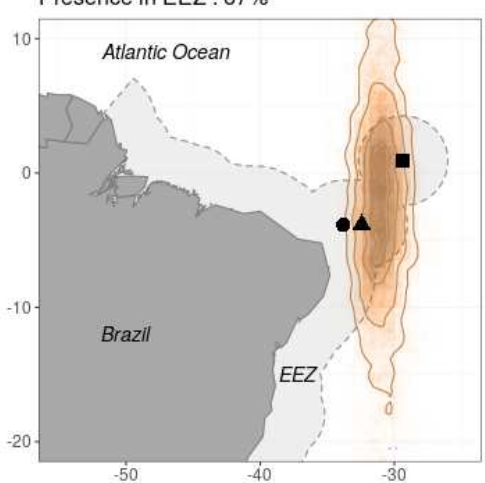

(f) Wet Utilization Distribution Presence In EEZ : $85 \%$

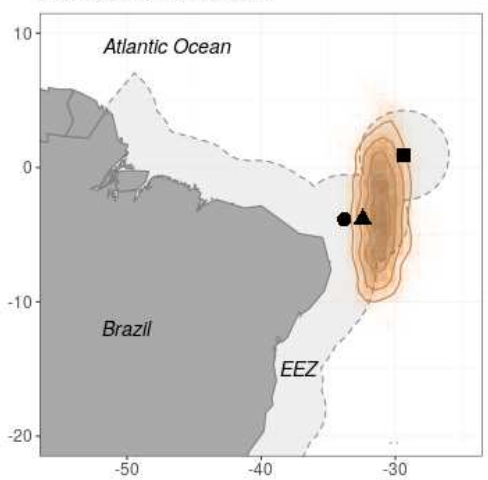

- Fernando de Noronha

- Atol das Rocas

- São Pedro São Paolo

Fig. 2 Maps of geolocation error (a and d) correspond to the geographical error range estimation of a GLS fixed at Fernando de Noronha, Brazil, based on the error structure presented in Fig. 1. Maps of utilization distributions ( $b$ and e) have been estimated using observed data from all GLSs. Maps of wet utilization distribution (c and $\mathrm{f}$ ) correspond to positions where the mean proportion of time spent on water is above $75 \%$. In ( $\mathrm{a}, \mathrm{b}$ and $\mathrm{c}$ ) all coordinates have been used, in $\left(\mathrm{d}\right.$, e and $\mathrm{f}$ ) positions with temperature deviation over $0.5^{\circ} \mathrm{C}$ were removed. Contours correspond to confidence intervals of 10, 25, 50, 75, and 90\%. Black points refer to main islands around FdN. EEZ stands for the Exclusive Economic Zone 


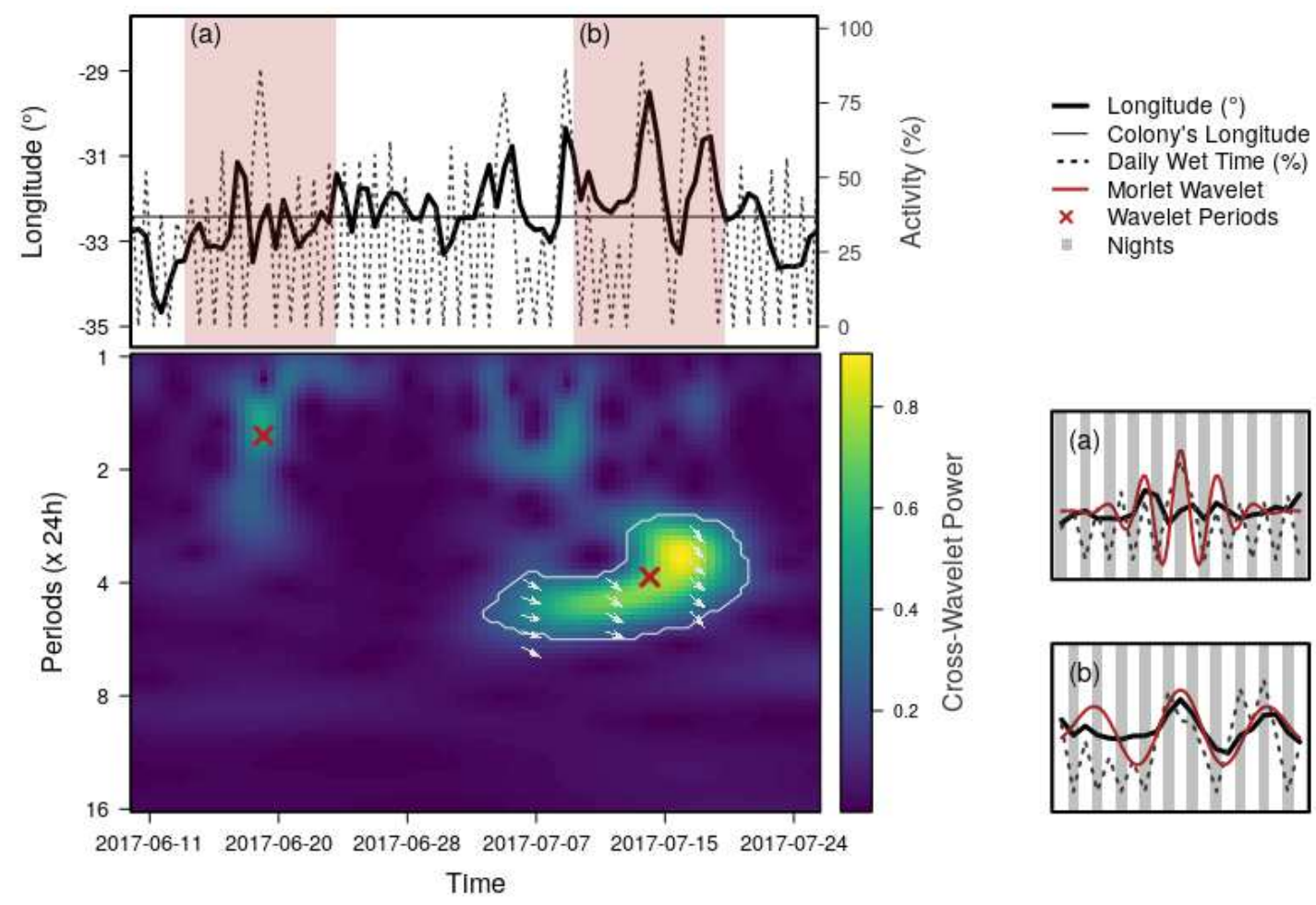

Fig. 3 Illustration of the cross-walelet theory based on GLS time-series derived from one individual and the associated cross-wavelet power matrix. The upper plot is longitude and saltwater immersion time-series. The bottom plot is the cross-wavelet power coefficient matrix. In such matrix, each power coefficient depends on one specific pair time/scale. The two plots on the right (a) and (b), illustrate how to compute such coefficients for the time/scale pairs marked with red crosses. In both cases, black lines consist in raw time-series for distinct time-windows, red lines show the Morlet wavelet with associated period, and grey rectangles show nights. Finally, coefficient matrix with significant synchronicity $(p<0.01$; lower left panel) are contoured with white lines, and white arrows illustrate the difference of phases between these synchronized time-series. Arrows pointing to the right (respectively left) indicate that the two series are in phase (respectively anti-phase) 


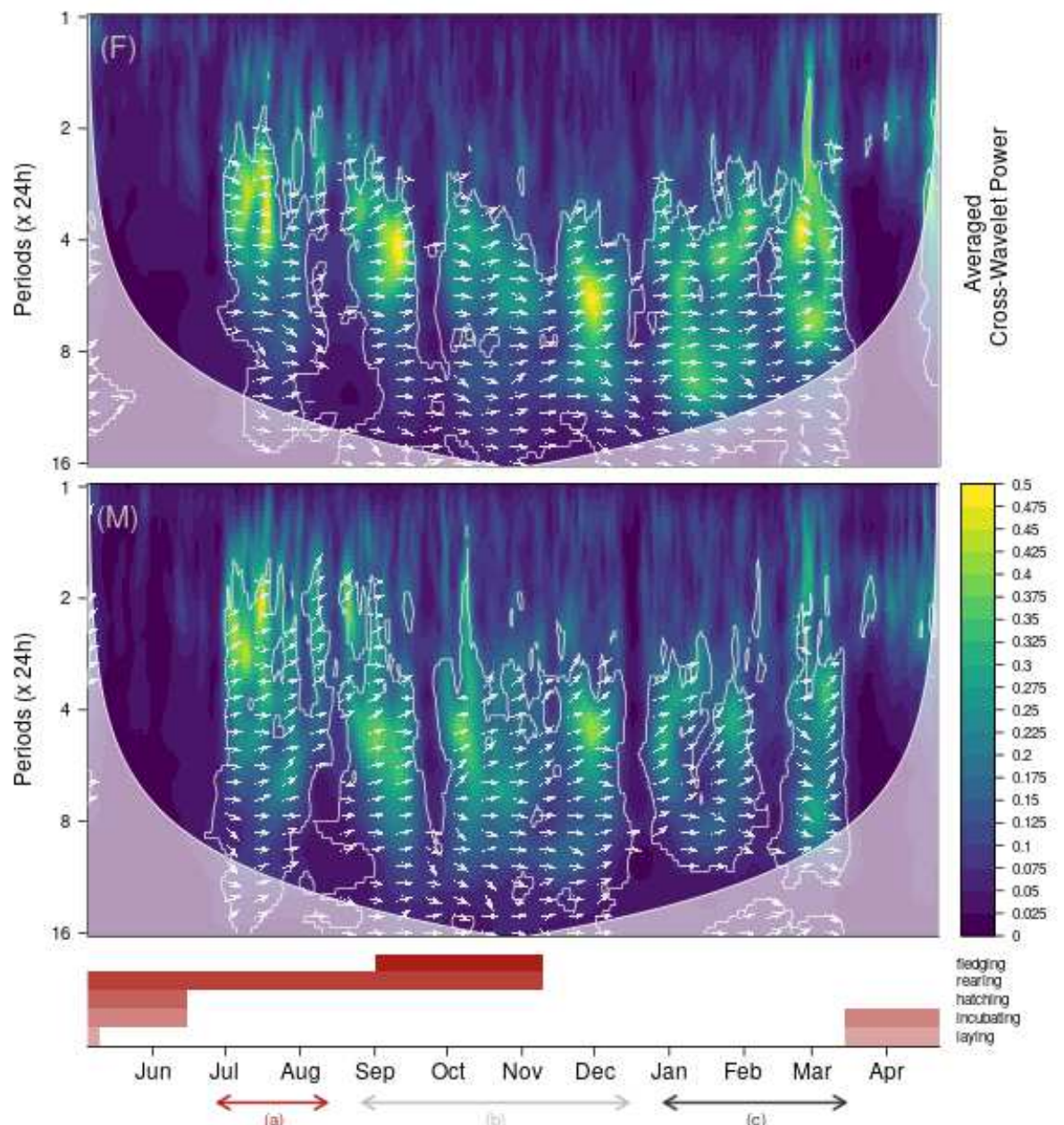

(a)

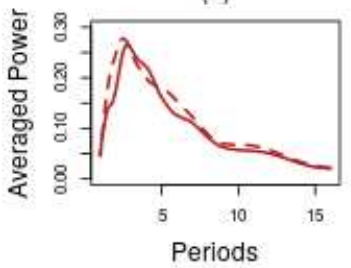

(b)

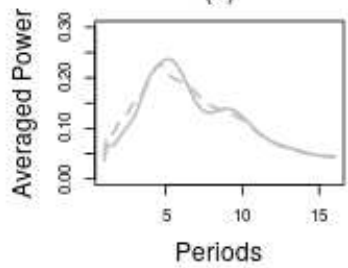

(c)

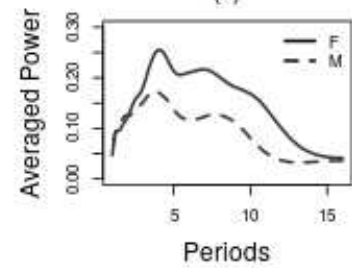

Fig. 4 Averaged cross-wavelet matrixes of longitude and activity time-series based on the analysis of all GLSs over the whole deployment for females $(\mathrm{n}=14 ;(\mathrm{F})$ ) and males $(\mathrm{n}$ $=17 ;(\mathrm{M}))$. White lines contour the time/period pairs where at least one individual has shown significant joint-periodicity between the two time-series. White arrows illustrate the difference of phases between the two time-series (see Fig. 3 for further explanations). The white area corresponds to the cone of influence (sensu Cazelles et al., 2008). The different stages of the phenology of masked boobies are indicated for Fernando de Noronha (center panel), Brazil, based on in situ observations. Lower panel show the averaged power over the three respective time-windows: (a) early chick-rearing, (b) late chick-rearing to post-breeding and (c) pre-breeding periods. Individual analysis are available on a GitHub repository (AmedeeRoy/WaveLightGLS) 
(a) Early chick-rearing
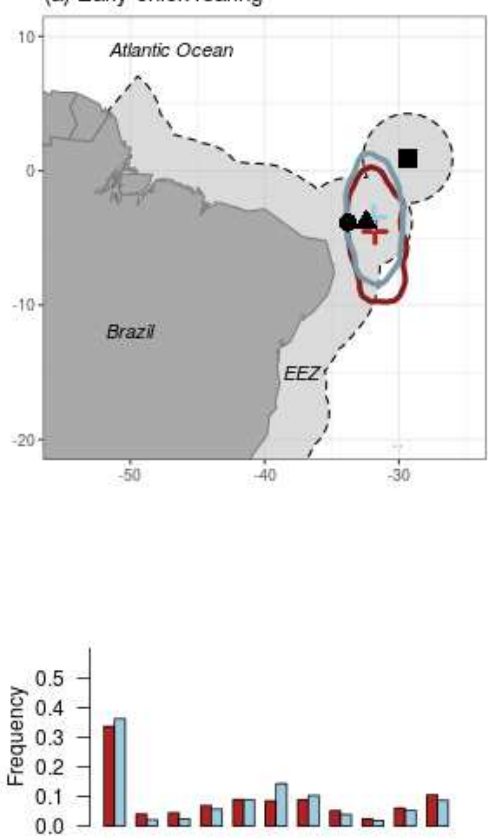

0102030405060708090100 Proportion of time in water $(\%)$

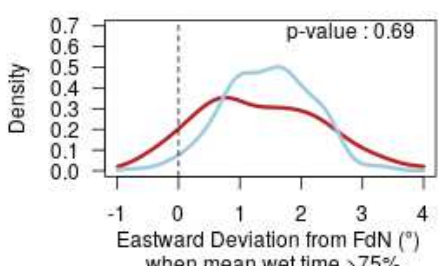

(b) Late chick-rearing to post-breeding
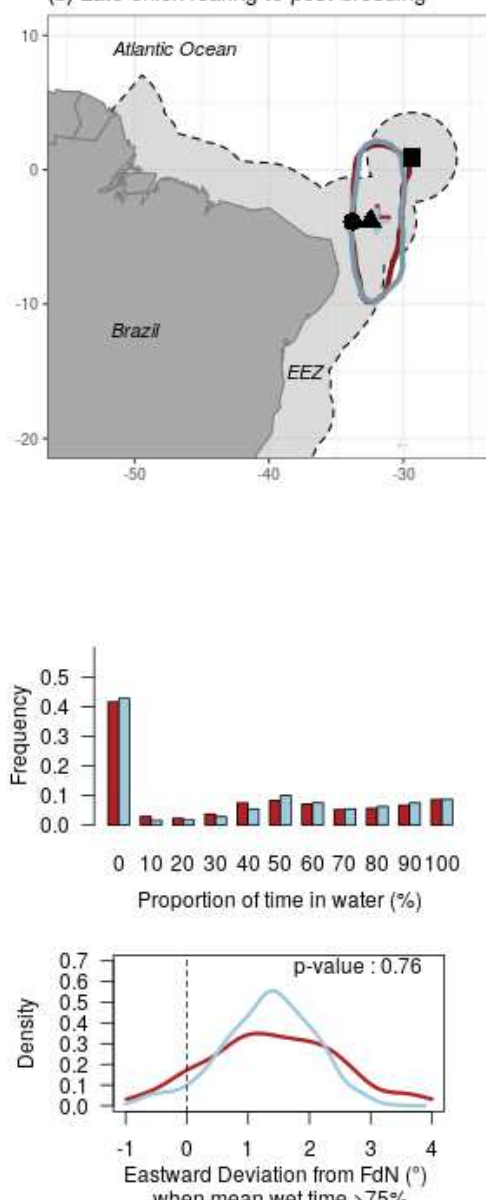

(c) Pre-breeding

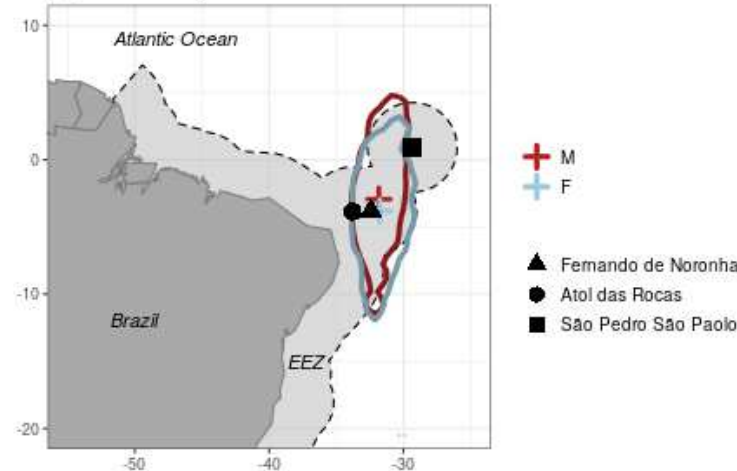

0102030405060708090100 Proportion of time in water $(\%)$

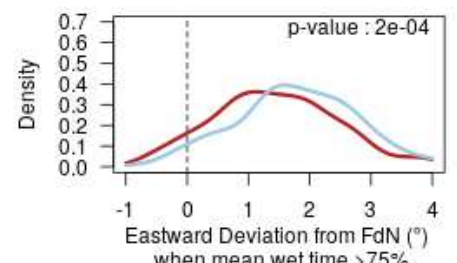

Fig. 5 Sex-specific utilization distributions for specific time-windows, where columns correspond to time-windows described in Fig. 4. (a) early chick-rearing, (b) late chick-rearing to post-breeding and (c) pre-breeding periods. Maps illustrate the utilization distribution by sex (F: females-light blue, M: males-red) for the associated periods. Contours represents utilization distribution of $90 \%$, and crosses the mean positions. Black points refer to main islands around FdN. Histograms (center panels) show at which frequency birds spent proportion of time rather in wet or dry environment during the associated period. Density plots (lower panels) illustrate the eastward deviations of positions with activity higher to $75 \%$ for the associated periods. p-values specify the significance of difference in mean between the two distributions derived from Welch Two Sample t-test 
Figures
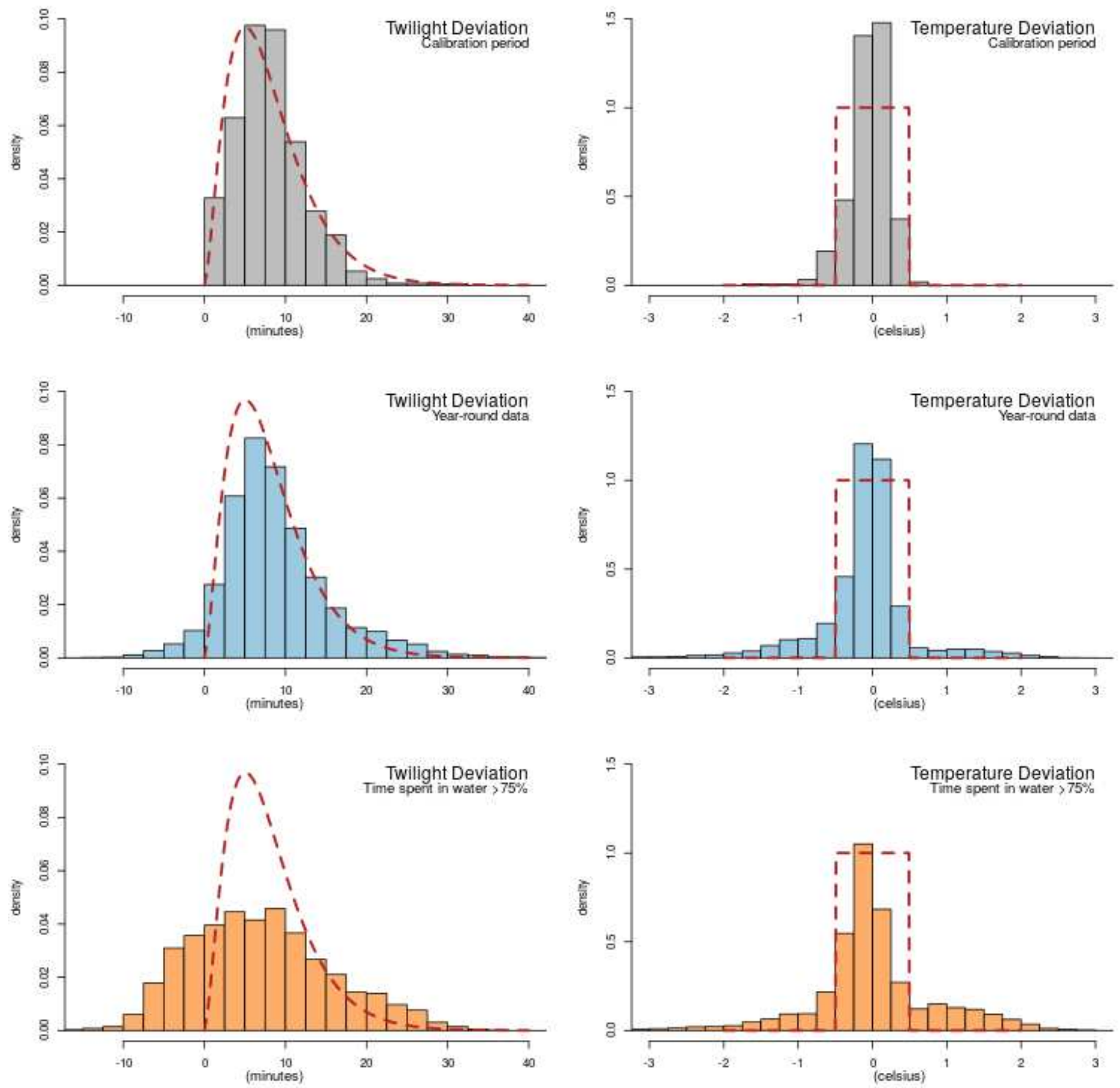

Figure 1

See the Manuscript Files section for the complete figure caption. 
(a) Error Range Estimation Presence In EEZ : $83 \%$

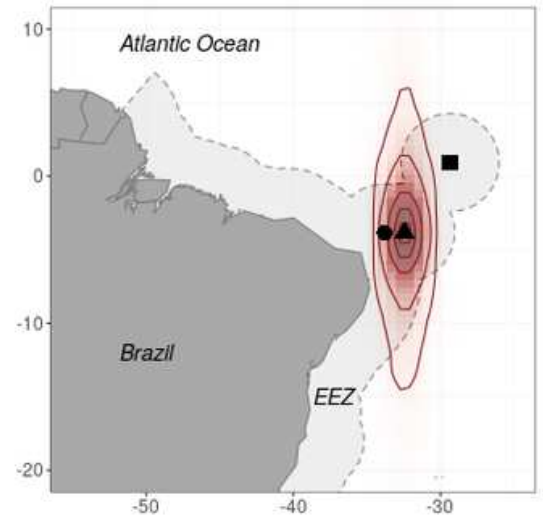

(d) Error Range Estimation Presence In EEZ : $95 \%$

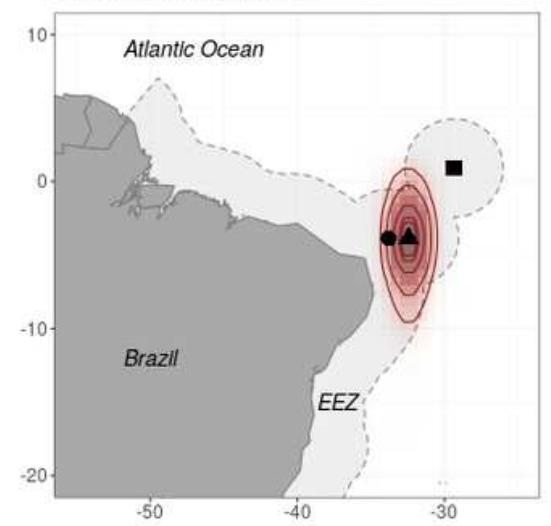

(b) Utilization Distribution Presence In EEZ : $77 \%$

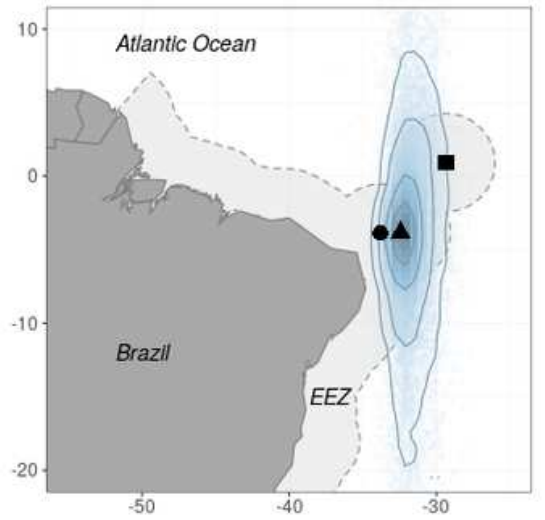

(e) Utilization Distribution Presence in EEZ : $93 \%$

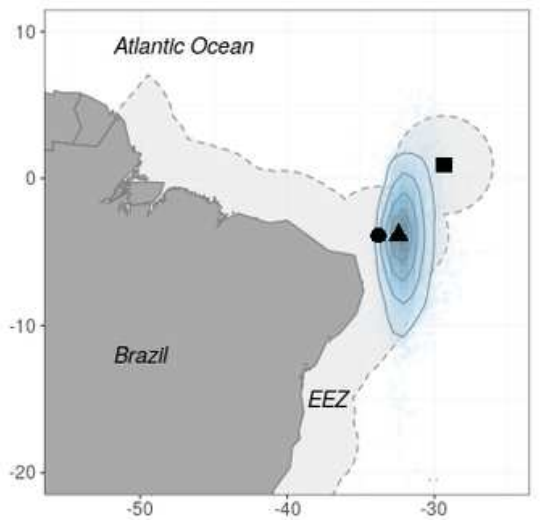

(c) Wet Utilization Distribution Presence in EEZ : $67 \%$

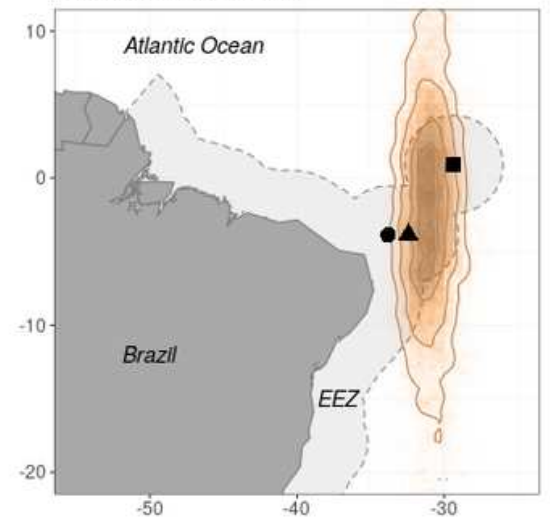

(f) Wet Utilization Distribution Presence In EEZ : $85 \%$

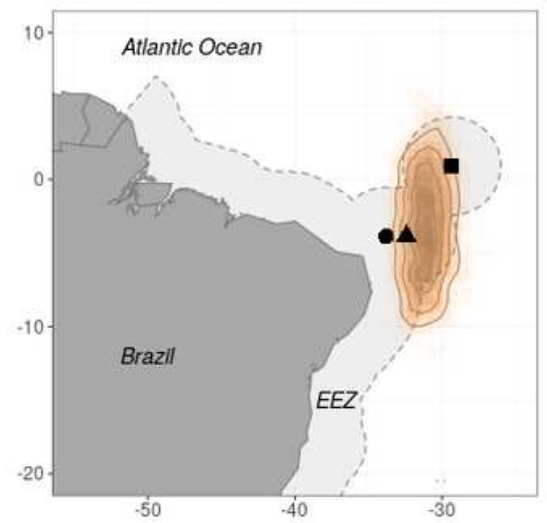

- Fernando de Noronha

- Atol das Rocas

- Sâo Pedro São Paolo

\section{Figure 2}

See the Manuscript Files section for the complete figure caption. 

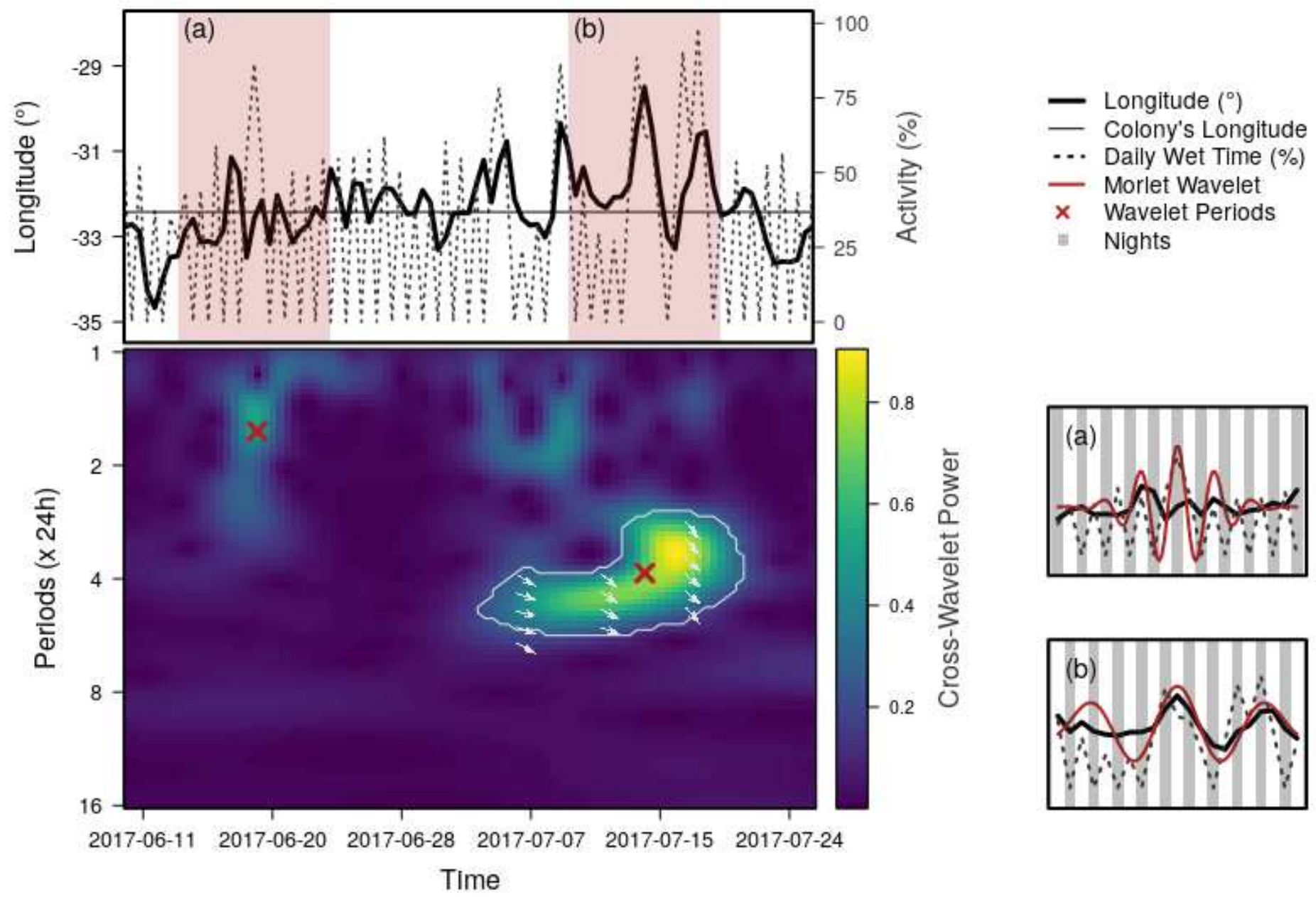

Figure 3

See the Manuscript Files section for the complete figure caption. 

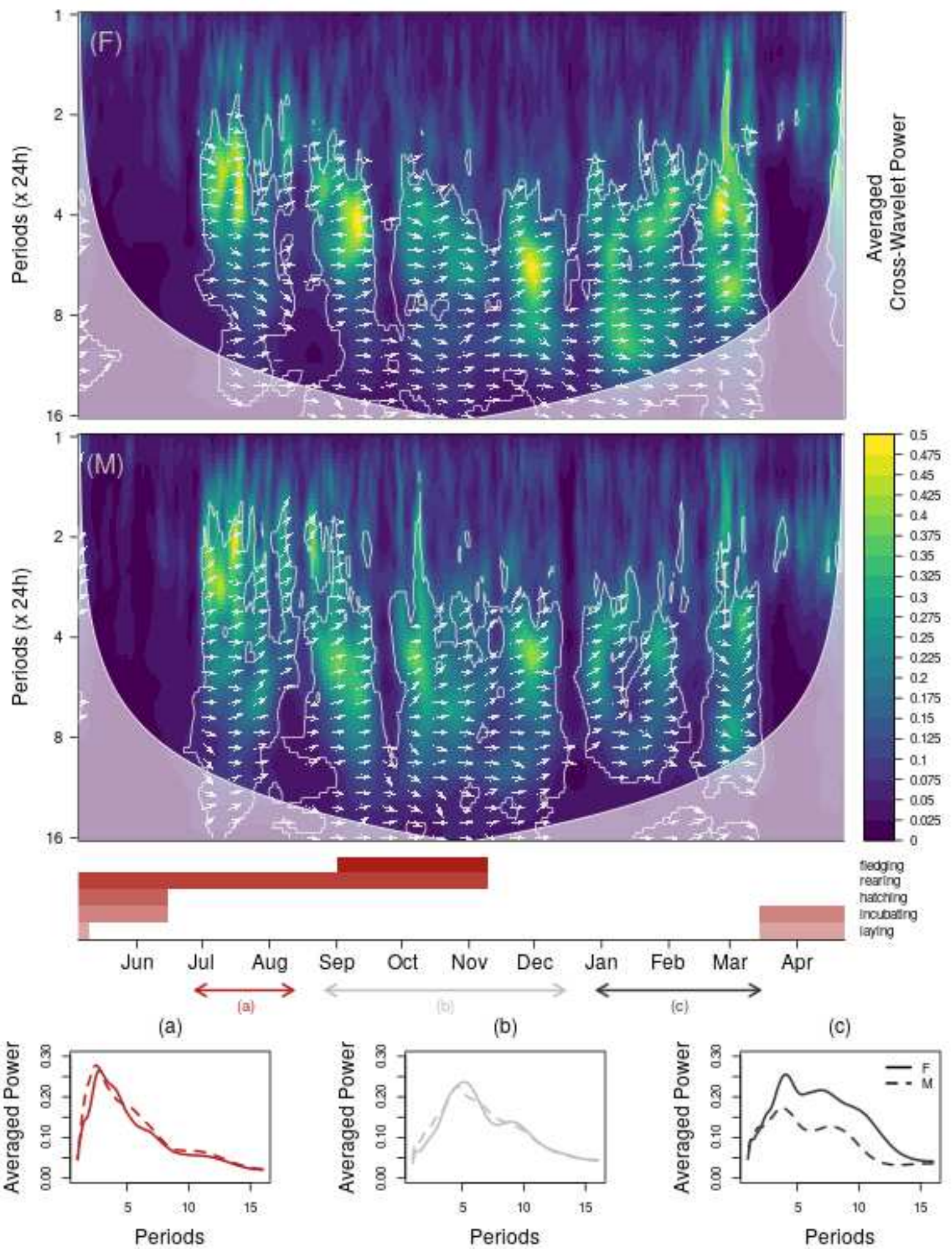

tledging

nascring

incubating laping

Figure 4

See the Manuscript Files section for the complete figure caption. 
(a) Early chick-rearing
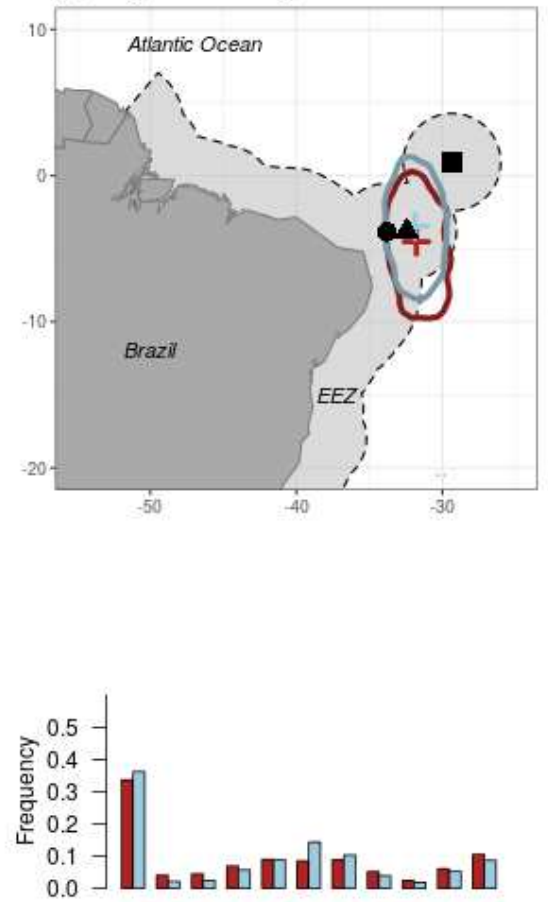

0102030405060708090100 Proportion of time in water (\%)

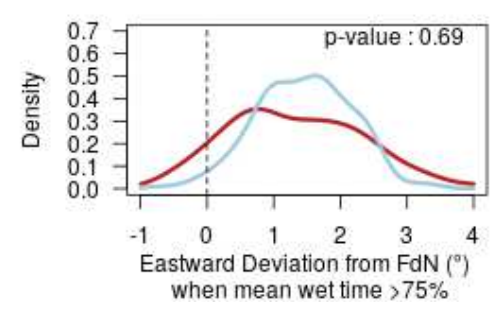

(b) Late chick-rearing to post-breeding
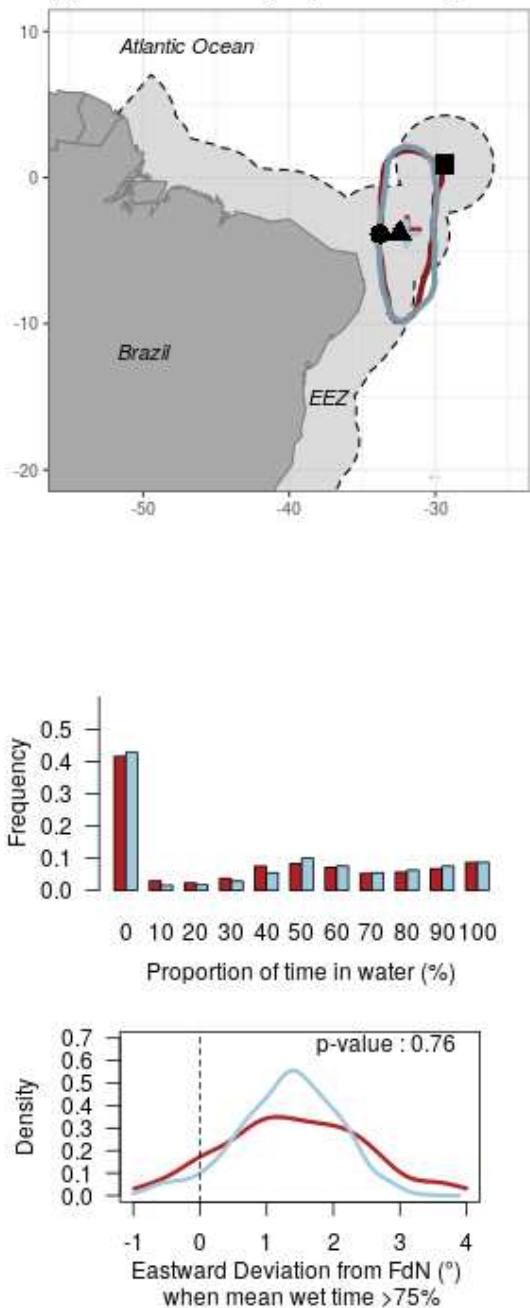

(c) Pre-breeding

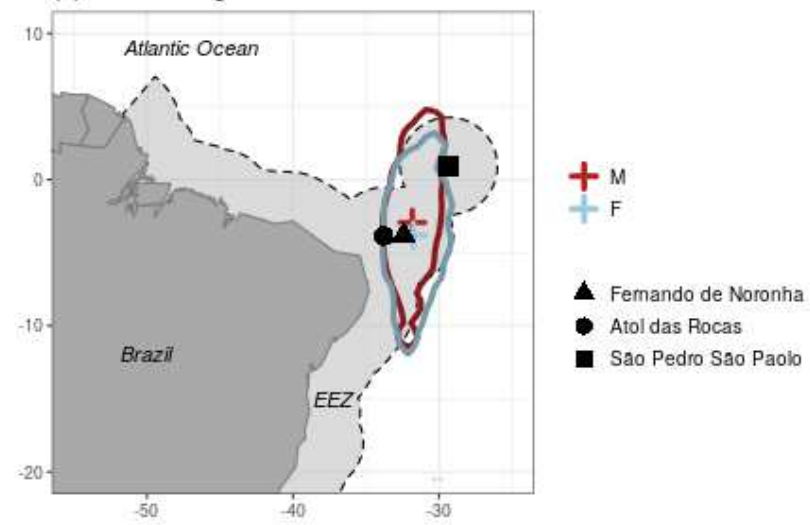

Figure 5

See the Manuscript Files section for the complete figure caption.
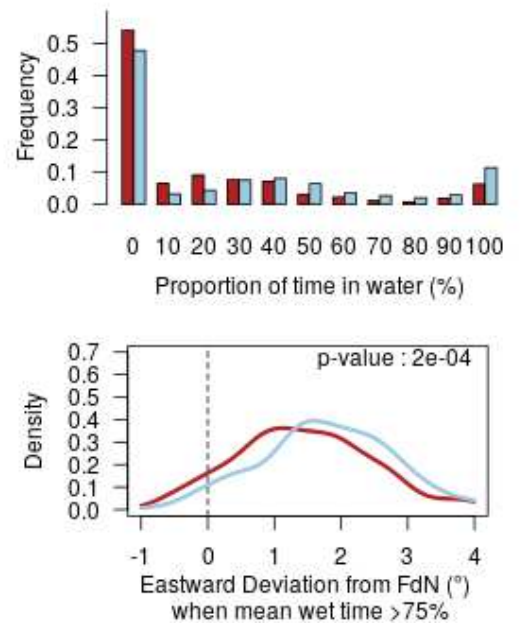